\title{
Política Educacional: Uma Análise sobre a Educação Pública e a Formação dos Jovens
}

\author{
Maria Lucineide Caetana Barbosa Sampaio ${ }^{l}$
}

Resumo: O presente artigo discute sobre as preocupações relacionadas aos jovens estudantes do Ensino Médio, bem como faz uma análise das Políticas Públicas existentes na educação básica, levando em consideração todas as problemáticas atuais e a relação entre jovens, escola e mercado de trabalho.

Faz-se necessário que se compreenda o momento social em que os adolescentes do século XXI estão inseridos, suas reais necessidades e seus anseios, para que se faça uma melhor análise de como a educação vem ajudando o jovem. No momento histórico, político e social, pode-se apontar as principais falhas e a contradição existente entre aquilo que se espera da educação básica e o que ela oferece na realidade. Para tanto, faz-se necessário compreender o conceito de políticas educacionais e como se constrói uma Política Pública; como elas agem na amenização dos problemas existentes na sociedade e o que pode ser feito para que essas políticas garantam de verdade os direitos de cidadania dos jovens estudantes do Ensino Médio.

Palavras-Chave: Políticas Públicas; Educação; Ensino Médio.

\section{Educational Policy: an Analysis of Public Education and Youth Formation}

\begin{abstract}
This article discusses the concerns related to young high school students, as well as an analysis of existing public policies in basic education, taking into account all current problems and the relationship between youth, school and the labor Market. It is necessary to understand the social moment in which the adolescents of the 21 st century are inserted, their real needs and their wishes, so that a better analysis can be made of how education has been helping young people. Considering the historical, political and social moment, there are perceivable flaws and contradictions between what is expected of basic education and what it offers in reality. Therefore, it is necessary to understand the concept of educational policies and how to build a public policy; How they act to alleviate existing problems in society and what can be done to ensure that these policies truly guarantee the citizenship's rights of young high school students.
\end{abstract}

Keywords: Public Policies; Education; High school.

\section{Introdução}

A modalidade de Ensino Médio e as Políticas Públicas que o implementam vem sendo tema de estudos e investigações dos pesquisadores que estão ligados à área da Política, Educação e Trabalho.

\footnotetext{
${ }^{1}$ Professora do ensino fundamental e médio, habilitada em Letras pelas Universidade Regional do Cariri (URCA) e especializada em Planejamento Educacional. Aluna regularmente matriculada no curso de Mestrado pela Anne Sullivan University. E-mail: lucineide-caetana@hotmail.com.
} 
Pode-se encontrar atualmente uma vasta literatura sobre as problemáticas, envolvendo a juventude e a sua relação com o Ensino Médio e o mercado de trabalho. Todavia é importante ouvir e entender o jovem, analisar quais politicas estão dando certo e o que ainda pode ser feito ou revisado, para garantir que mais jovens não acabem indo pelo caminho do abandono escolar.

É necessário que o jovem compreenda a importância dele concluir o ensino básico, que sendo uma etapa fundamental para a sua formação social, política e cidadã, não deve ser interrompida ou atropelada.

Deve-se notar que a juventude que se tem no momento atual já não aceita várias coisas que estão sendo impostas na escola. Eles questionam ou agem com indisciplina, querendo mudanças. Os mesmos não encontram no material didático motivações para estudar determinados assuntos, ou até mesmo não encontram as respostam que precisam para seus anseios e problemas sociais . Assim:

\begin{abstract}
Entender o jovem do Ensino Médio [...] significa superar uma noção de homogeneizante e naturalizada desse estudante, passando a percebê-lo como sujeito com valores, comportamentos, visões de mundo, interesses e necessidades singulares. Além disso, deve-se também aceitar a existência de pontos em comum que permitam trata-lo como uma categoria social. Destacam-se sua ansiedade em relação ao futuro, sua necessidade de se fazer ouvir e sua valorização de sociabilidade. Além das vivencias próprias da juventude, o jovem está inserido em processos que questionam e promovem sua preparação para assumir o papel de adulto, tanto no plano profissional quanto no social e familiar. (BRASIL, 2013, p.155)
\end{abstract}

As Políticas Públicas existentes, e a escola como um todo, devem ser analisadas e estudadas, levando em consideração que o jovem é um sujeito ativo na sociedade em que está inserido. Ao contrário do que muitos pensam, ele não se encontra passivos diante da sua realidade e do mundo.

É necessário, então, um breve estudo sobre o que são políticas educacionais, o que a educação tem feito pelos jovens e pela garantia desse direito básico, o que melhorou e evoluiu durante os últimos anos e o que precisa ser repensado e avaliado. Isso sem a intenção de querer apontar culpados ou inocentes, apenas para tentar compreender que, a educação sendo um longo caminho, ainda há muito a se percorrer. Muito ainda precisa ser feito pelo poder público para que a educação realmente aconteça. 
Id on Line Revista Multidisciplinar e de Psicologia

Id on Line Multidisciplinary and Psycology Journal

\section{Políticas públicas educacionais.}

Quando se fala de política a primeira coisa que se vem em mente é corrupção, uma perece ser sinônimo da outra, uma ideia totalmente equivocada. Nascida na Grécia Antiga, a política é algo indispensável para a organização da sociedade. Em sua definição pode se dizer que ela é um conjunto de regras que servem para a organização de um país, instituição, até mesmo dos lares de cada cidadão. Do contrário se tem o termo "politicagem", que serve para designar toda essa corrupção que é vista dentro do sistema político brasileiro.

Porém, não é de interesse do presente artigo adentrar nesta discussão sobre politicagem e corrupção. O que interessa é fazer um breve apanhado do que envolve o termo política, para que se possa introduzir o conceito mais a diante de "políticas públicas".

Sabe-se que o Estado é o responsável pela organização do país, e que é seu dever prover as necessidades da população, garantindo-lhe seus direitos universais e constitucionais. Para tanto é necessário que haja programas e ações voltados especialmente para algumas necessidades em especifico.

De acordo com o autor Teixeira (2002, p.2) políticas públicas são:

[...] diretrizes, princípios norteadores de ação do poder Público; regras e procedimentos para as relações entre Poder Público e sociedade, mediações entre atores da sociedade e do Estado. São, neste caso, politicas explicitadas, sistematizadas ou formuladas em documentos (leis, programas, linhas de financiamentos) que orientam ações que normalmente envolvem aplicações de recursos públicos. Nem sempre, porém, há compatibilidade entre as intervenções e declarações de vontade e ações desenvolvidas. Devem ser consideradas também as "não ações", as omissões como forma de manifestação de política, pois representam opções e orientações dos que ocupam cargos.

Desta forma, pode-se afirmar que políticas públicas são todas as ações que um governo faz, ou deixa de fazer, para atuar em um determinado problema social. E só é possível haver políticas públicas se houver a participação dos atores sociais. Assim , pode-se falar de políticas educacionais como ponto mais específico do tratamento da educação, que em geral se aplica às questões da escola.. Em outras palavras, pode-se dizer que políticas públicas educacionais estão relacionadas com a educação escolar. 
Id on Line Revista Multidisciplinar e de Psicologia

Id on Line Multidisciplinary and Psycology Journal

\section{Importância das políticas educacionais para a educação brasileira}

No Brasil a educação se iniciou com os trabalhos dos jesuítas, que como se sabe, dedicaram-se a ensinar os índios a ler e escrever, com propósitos religiosos. Todavia a educação desde o início da sua implementação no país era de interesses elitista, poucos tinham acesso, poucos se formavam e podiam ter acesso à educação superior. Estudos relatam que a maioria das pessoas no Brasil Colônia era analfabeta. Desta forma, pode-se notar a grande importância que foi o fato do Estado passar a ter responsabilidade com a educação brasileira, tornando a escola uma instituição gratuita, laica e publica.

A educação como direito universal e gratuito só foi possível graças a criação de políticas públicas, que visando atender às necessidades da sociedade, atuam em várias áreas e envolvem diversos atores sócias.

As políticas públicas são de responsabilidades do Estado e devem estar em concordância com as organizações e entidades públicas, para que se possa conhecer e criar planos de ação que atuem na resolução dos problemas sociais. Para que fosse criada as políticas educacionais foram necessárias as participações populares, os movimentos sociais e as reivindicações em favor das resoluções dos problemas relacionados à educação brasileira.

As mudanças de grande importância para a educação brasileira vieram com o surgimento da Lei de Diretrizes e Bases da Educação Nacional (LDB), do Plano Nacional de Educação (PNE), do Plano de Desenvolvimento da Educação (PDE) e da Educação de Jovens e Adultos (EJA). A LDB foi implementada em 1996, regulamentando a educação pública, definindo os objetivos e finalidades da educação básica e superior.

De acordo com o Art n ${ }^{\circ} 01$, a educação é definida como algo que passa a abranger "os processos formativos que se desenvolvem na vida familiar, na convivência humana, no trabalho, nas instituições de ensino e pesquisa, nos movimentos sociais e organizações da sociedade civil e nas manifestações culturais". O PNE, lei de número 10.172, promulgada em 09 de janeiro de 2001, "determina diretrizes, metas e estratégias para a política educacional" (Ministério da Educação), e tem validade de dez anos.

O PDE foi criado para auxiliar a gestão escolar, baseando-se em um planejamento participativo, e destinado ao auxílio a escolas públicas, a fim de melhorar a gestão escolar. O 
Id on Line Revista Multidisciplinar e de Psicologia

Id on Line Multidisciplinary and Psycology Journal

MEC repassa recursos financeiros para as escolas priorizadas pelo programa. O PDE é uma ferramenta de gestão e só será de utilidade se ajudar realmente a comunidade escolar a identificar e a enfrentar os problemas de sua convivência. Para isso, é necessário que o resultado da pesquisa corresponda a sua realidade e seja repensado de forma coletiva .

A educação de jovens e adultos no Brasil aconteceu no período colonial, e nesta época a igreja era responsável pela educação. Os jesuítas tinham a incumbência de ensinar os índios a ler e escrever, para que eles servissem a igreja e realizassem também um trabalho manual.

Sabe-se , porém , que a EJA vai muito mais além de ensinar a o aluno a ler e a escrever. Os estudantes da EJA são pessoas que na idade regular não puderam estudar, ou desistiram da sala de aula por não terem se sentido atraídos pelos conteúdos.

A educação de jovens e adultos (EJA) não é algo muito recente, iniciou-se com a vinda dos Jesuítas, por volta de 1549, e durante séculos ela permaneceu em seu poder.

Com a educação como direito do cidadão e dever do estado todos os brasileiros, sem distinção de raça, sexo ou posição social puderam ter a mesma oportunidade de frequentar uma escola regulamentada pela LDB (Lei de Diretrizes e Bases da Educação Nacional) a Lei 9.394/96, com o grande objetivo de ler e escrever.

A grande mudança veio com a promulgação da constituição de 1988, onde a educação passa a ter como objetivos principais a qualificação para o mercado de trabalho, o desenvolvimento pessoal e o preparo para o exercício da cidadania. Entende-se que ela é fundamental para a superação das desigualdades sócias, para o crescimento sócio e econômico do país e para formação de profissionais qualificados. Com a Constituição de 1988 foi reservado uma parte dos recursos públicos, destinados à educação, garantindo este direito fosse mantido.

Todos as políticas educacionais criadas a partir das necessidades e com participação popular refletem uma ideia de que um país não pode crescer sem educação e vai além: provar que a mesma deveria ser uma prioridade, já que os problemas sociais são diversos e atingem uma grande parcela da população de forma desigual. Porém é necessário pensar que é de grande importância trabalhar e agir mais em favor da educação, pois é ela que de alguma forma ou de outra dá aos indivíduos a chance de ter as mesmas oportunidades na vida e na superação das desigualdades sociais. Desta forma o autor Azevedo (2010) adverte que "na hierarquia dos problemas nacionais, nenhum sobreleva em importância e gravidade ao da educação, nem 
Id on Line Revista Multidisciplinar e de Psicologia

Id on Line Multidisciplinary and Psycology Journal

mesmo os de caráter econômico lhe podem disputar a primazia nos planos de reconstrução nacional".

\section{As Diretrizes Curriculares Nacionais para o Ensino Médio frente a realidade sócio educacional}

Com o advento da tecnologia, é um fato a afirmação de que a sociedade se modificou como um todo, em plena era pós-moderna a sociedade brasileira vive em constantes modificações políticas, sociais, culturais e principalmente as mudanças de comportamento. Os jovens de hoje são de certa forma diferentes da juventude de uma década atrás.

No contexto atual há muito mais coisas que se tornam mais atraentes ao jovem do que a escola, o que de certa forma leva os adolescentes a quererem ter a sua própria renda, em função de poder disfrutar todas as modernidades desta era tecnológica ,e, principalmente, pelo fato de pretenderem se tornar independentes cada vez mais cedo. Logo, acompanhando as mudanças sociais e comportamentais, a educação brasileira tenta modificar-se para manter os alunos na escola e atender as necessidades atuais referentes a educação e sociedade.

Todavia com relação ao Ensino Médio, "sua estrutura, seus conteúdos, bem como suas condições atuais estão longe de atender as necessidades dos estudantes, tanto nos aspectos da formação de cidadania como para o mundo do trabalho". (BRASIL, 2013, p.145)

O Ensino Médio como continuidade e complementação da educação básica tem um papel fundamental na formação social do jovem e para sua preparação ao mercado de trabalho, bem como o seu ingresso para o ensino superior.

Segundo Gómez $(1998$, p. 15) “a escola deve prepará-lo para que se incorpore à vida adulta e pública, de modo que se possa manter a dinâmica e o equilíbrio nas instituições, bem como as normas de convivência que compõem o tecido social da comunidade humana". Como função de socialização a educação de modo geral deve levar o jovem ao exercício da cidadania. O Ministério da Educação propõe em relação ao Ensino Médio uma educação de preparação para a vida, não apenas para o vestibular, de modo que os alunos possam desenvolver várias competências, trabalhando a contextualização e interdisciplinaridade. 
De acordo com as Diretrizes Curriculares Nacionais da Educação Básica:

\begin{abstract}
A precípua da educação, de um modo geral, e do ensino Médio - última etapa da educação Básica - em particular, vai além da formação profissional, e atinge a construção da cidadania, é preciso oferecer aos nossos jovens novas perspectivas culturais para que possam expandir seus horizontes e dotá-los de autonomia intelectual, assegurando-lhes o acesso ao conhecimento historicamente acumulado e à produção coletiva de novos conhecimentos, sem perder de vista que a educação também é, em grande medida, uma chave para o exercício dos demais direitos sociais. (BRASIL, 2013, p.145)
\end{abstract}

Na realidade o que ocorre nas instituições do Ensino Médio está um pouco distante do desenvolvimento esperado e das competências e objetivos da LDB (Lei de Diretrizes e Bases da Educação). São poucos os jovens que concluem o ensino básico, que compreendem a diversidade cultural; desenvolvem uma consciência de responsabilidade política; tornam-se indivíduos autônomos; que têm motivações para continuar dedicando-se aos estudos e a leitura; atuam no mercado de trabalho com ética profissional; sabem utilizar as diversas linguagens do mundo contemporâneo e que têm capacidade crítica de não aceitar tuto que lhe é oferecido, sem antes procurar questionamentos e debates.

É uma pequena minoria que conclui o ensino Médio com capacidade de desenvolver tais competências e habilidades, sendo que nesta, pode-se dividir em grupos os que desenvolveram mais alguns pontos específicos e quais desenvolveram outros pontos. É possível que se encontre jovens adolescentes que desenvolveram a cidadania, todavia não se sentem motivados para continuar firmes nos estudos, ou não sabem utilizar criativamente as novas ferramentas e linguagens do mundo moderno. O fato é que "vários movimentos sinalizam no sentido de que a escola precisa ser repensada para responder aos desafios colocados pelos jovens" (BRASIL, 2013, p. 146).

Nesta discussão sobre as habilidades e competências, os concludentes do Ensino Médio deveriam demostrar um bom desempenho, mas na verdade a realidade que se tem na atual sociedade brasileira é de que o jovem não sai realmente preparado para o mercado de trabalho. Logo é possível concluir que "No sentido geral, da forma como está organizado na maioria das escolas , o Ensino Médio não dá conta de todas as suas atribuições definidas na Lei de Diretrizes e Bases da Educação Nacional (LDB)" (BRASIL, 2013, p 146) assim se faz necessária uma elaboração de novas Diretrizes Curriculares Nacionais para o ensino Médio, “em virtude das 
Id on Line Revista Multidisciplinar e de Psicologia

Id on Line Multidisciplinary and Psycology Journal

novas exigências educacionais decorrentes da aceleração da produção de conhecimentos, da ampliação do acesso às informações, da criação de novos meios de comunicação, das alterações do mundo do trabalho e das mudanças de interesses dos adolescentes" ( BRASIL, 2013, p 146).

De fato, é necessário repensar o que está sendo desenvolvido na escola. É importante analisar a forma como os alunos são avaliados, os projetos que precisam ser desenvolvidos, a maneira de integrar as várias disciplinas, o modo de utilização dos recursos tecnológicos integrados a aula, a forma de como aproveitar o tempo em sala e de como fazer com que não se torne apenas algo entediante.

É preciso desenvolver atividades práticas com os alunos, de forma que os tirem da sua acomodação e da monotonia da sala de aula. É de grande importância que se busque meios de fazer com que o adolescente se sinta motivado a permanecer na escola, cumprindo seus deveres de forma consciente.

\section{Relação entre jovens, escola e trabalho}

Atualmente, percebe-se que há uma grande ansiedade por parte jovens de entrarem no mercado de trabalho. Alguns deles já vivem esta realidade antes mesmo de concluírem o Ensino Médio. O fato é que seja para auxiliar a família ou para suprir suas próprias necessidades, muitos dizem não ter paciência para com os estudos, e que preferem o trabalho. Por este motivo acabam abandonando a escola sem pensar nas consequências que esta atitude trará num momento posterior.

Para muitos estudantes o grande motivo de estarem na escola ainda é por conta do mercado de trabalho. Desejam se preparar para o mundo do trabalho e por isso procuram cursar o ensino superior, logo após a conclusão do médio.

Os jovens adolescentes "vivem ansiosos por uma escola que lhes proporcione chances mínimas de trabalho e que se relacione com suas experiências presentes". (BRASIL, 2013, p.155).

Por mais que se fale em cidadania e importância do conhecimento e do saber para a formação do pensamento crítico e desenvolvimento do sujeito social , estas motivações e este 
discurso podem ainda não atrair o jovem. Parece não ser o suficiente, ou até mesmo estar fora de sua realidade social.

Percebe-se que ele tem o trabalho como uma de suas principais preocupações do presente, não almejando nada mais importante para seu futuro. Ate parece que o "mundo do trabalho estar mais presente na vida desses sujeitos do que a escola" (BRASIL, 2013, p.156).

Os estudantes do Ensino Médio estão bem mais atentos aos acontecimentos políticosociais e refletem como estes acontecimentos podem afetar nos seus planos e na sua existência. “Os jovens [...] percebem estas modificações e criam novas expectativas em relação às possibilidades de inserção no mundo do trabalho e em relação ao papel da escola nos seus projetos de vida" (BRASIL, 2013, p.157).

Desta forma é imprescindível que a escola passe a ver os jovens além das suas condições de "apenas estudantes". É de fundamental importância que a escola aproxime os conteúdos didáticos da realidade dos jovens estudantes.

É importante salientar que esta inserção do jovem cada vez mais cedo no mercado de trabalho tem prejudicado a sua formação educacional e por vezes mantém um ciclo em que o abandono escolar e a inteira dedicação ao trabalho acabam fazendo com que jovens se tornem adultos mais cedo, que reproduzam a alienação do capitalismo ,dando seguimento à população de senso comum a viver apenas para o trabalho e para sua sobrevivência, que segue sem conhecimento critico ou empírico, capaz de lhe ajudar a enfrentar a realidade social e política.

Sobre esta questão Oliveira nos diz que:

Destacar a importância da articulação entre a formação geral e a formação profissional ainda se coloca como pedagógica e politicamente importante, uma vez que deve haver e vem existindo uma contínua e ininterrupta preocupação por parte daqueles que pesquisam na área de Trabalho e Educação e/ou Ensino Médio de reafirmar o quanto o processo de formação profissional não pode resumir-se apenas à apropriação de saberes práticos e úteis ao mercado de trabalho. Cada vez mais, a luta política por um Ensino Médio que objetive a formação "integral" dos educandos impõe-se como necessária e consequente. (2009, p.53).

Assim a escola deve se aproximar do mercado de trabalho e da realidade social dos jovens brasileiros para que não ocorra o abandono escolar. Mas não deve apenas prender-se a 
este ponto, pois é necessário que ao longo da educação básica o aluno tenha desenvolvido diversos saberes e habilidades.

É necessário repensar as políticas públicas que auxiliam o Ensino Médio, promovendo debates sobre questões que sejam do interesses dos jovens e adolescentes, bem como de sua realidade social e cultural. É preciso maior articulação com outras políticas públicas , para que assim se possa proteger e garantir os direitos e necessidades da juventude.

\section{Considerações Finais}

Percebe-se que as Políticas Educacionais estão modificando a educação nacional, atendendo as diversas necessidades e atuando nas diversas problematizações que envolvem a escola e seus frequentadores.

Todavia a realidade ( por mais que o contexto atual seja melhor do que a uma década atrás) , ainda enfrenta várias problematizações e questões como falta de interesse, indisciplina, abandono escolar, alunos que concluem a educação básica sem as devidas competências e habilidades, quando na verdade deveriam ter e dominar as mesmas. Sem falar que professores relutam em permanecer na educação tradicional, e como se isso não bastasse ainda há os problemas de infraestrutura, de leitura e interpretação textual, etc.

A educação necessita de discursões, debates, estudos e pesquisas para que se possa construir novas ideias, pensar em novas políticas educacionais, encontrar outras soluções para as problemáticas vividas pelos jovens.

É preciso, portanto, aproximar as ações da escola com os interesses dos jovens, principalmente, que se observe suas reais necessidades, levando-se em conta a importância de seu progresso social e mental. Ainda se deve levar em consideração que apesar da educação não ter o poder de modificar a sociedade por si mesma, ela ainda é uma "importante estratégia de transformação, uma vez que a inclusão na sociedade contemporânea não se dá sem o domínio de determinados conhecimentos" (BRASIL, 2013, p.167) e por isto é fundamental que os jovens (mesmo já estando no mercado de trabalho) estejam na escola e completem a etapa da educação básica 
Id on Line Revista Multidisciplinar e de Psicologia

Id on Line Multidisciplinary and Psycology Journal

Apesar dos muitos avanços na tecnologia e na educação, ainda há muito a ser feito pelos jovens. É preciso estabelecer metas e estratégias que garantam aos mesmos matrícula e permanência na escola, de forma que saiam prontos a enfrentarem não só o mercado de trabalho, mas também sejam capazes de solucionar problemas do seu cotidiano.

\section{Referências}

AZEVEDO. Fernando de, et. Manifesto da Educação Nova (1932) e dos Educadores (1959). Coleção Educadores. Editora Massangana, Recife, 2010

BRASIL. Ministério da Educação. Secretaria de Educação Básica. Secretaria de Educação Continuada, Alfabetização, Diversidade e Inclusão. Secretaria de Educação Profissional e Tecnológica. Conselho Nacional da Educação. Câmara Nacional de Educação Básica. Diretrizes Curriculares Nacionais Gerais da Educação Básica/ Ministério da Educação, Secretaria de Educação Básica. Diretoria de Currículos e Educação Integral. Brasília: MEC, SEB, DICEI, 2013

INEP/MEC. Enciclopédia de pedagogia universitária: glossário vol. 2 / Editora-chefe: Marilia Costa Morosoni. - Brasília: Instituto Nacional de Estudos e Pesquisas Educacionais Anísio Teixeira, 2006.

GÓMEZ, A. I. Pérez. As funções sociais da escola: da reprodução à reconstrução crítica do conhecimento e da experiência. In: SACRISTÁN, J.

Gimeno; GÓMEZ, A. I. Pérez. Compreender e transformar o ensino. $4^{\mathrm{a}}$ ed. Porto Alegre: ArtMed, 1998.

OLIVEIRA, Adão Francisco de. Políticas públicas educacionais: conceito e contextualização numa perspectiva didática. In: OLIVEIRA, Adão Francisco de. Fronteiras da educação: tecnologias e políticas. Goiânia-Goiás: PUC Goiás, 2010

OLIVEIRA, Ramon de. Possibilidades do ensino médio integrado diante do financiamento público da educação. Educação e Pesquisa, São Paulo, v.35, n.1, p.051-066, jan./abr., 2009. Disponível em Http://www.scielo.br/pdf/ep/v35n1/a04v35n1.pdf Acesso em 22/06/2016.

TEIXEIRA, Elenaldo Celso. O papel das Políticas Públicas no desenvolvimento local e na transformação da realidade. Cadernos da AATR -BA (Associação de Advogados de Trabalhadores Rurais no Estado da Bahia), Bahia, p. 1-11, 2002. Disponível em: <http://www.dhnet.org.br/dados/cursos/aatr2/a_pdf/03_aatr_pp_papel. pdf >. Acesso em: 10 jan. 2011. 
Id on Line Revista Multidisciplinar e de Psicologia

Id on Line Multidisciplinary and Psycology Journal

BRASIL. Disponível < http://www.planalto.gov.br/ccivil_03/leis/L9394.htm>. Acesso em 16 de junho de 2016.

BRASIL. Disponível em <http://pne.mec.gov.br/>. Acesso em 16 de junho de 2016.

\section{Como citar este artigo (Formato ABNT):}

SAMPAIO, Maria L. C. B. Trabalho: uma abordagem social, ontológica e educacional. Id on Line Revista Multidisciplinar e de Psicologia, Fevereiro de 2017, vol.11, n.34, p. 150-161. ISSN: 1981-1179.

Recebido: 20.02 .2017

Aceito: 27.02 .2017 